\title{
Do homem tipográfico ao homem pixel - um estudo de caso do momento em que jornalistas de impresso se reconhecem como profissionais multimídia
}

\author{
Naiana Rodrigues da Silva \\ Universidade Federal do Ceará - naianarodrigues@gmail.com \\ Mestre em Comunicação Social pela UFC, professora substituta \\ do curso de Jornalismo da UFC, professora do curso de Jornalismo \\ da Faculdades Nordeste (Fanor) e repórter do jornal Diário do Nordeste.
}

\begin{abstract}
Resumo
O presente artigo apresenta alguns resultados de pesquisa de pós-graduação em nível de mestrado, concluída no ano de 2011. A investigação que deu corpo à dissertação buscou compreender a construção da identidade dos jornalistas de impresso, do jornal cearense Diário do Nordeste, em virtude da introdução de novas tecnologias móveis na rotina profissional. Especificamente, analisamos como o uso de um celular para gravação de vídeos digitais, pelos repórteres do impresso, veiculados no portal do periódico de 2008 a 2010, abalou as competências cognitivas desses profissionais (CUERRA, 2008), necessárias ao exercício diário do jornalismo, e a própria identidade destes sujeitos (HALL, 2008; 2006; 2000). Para tal, entrevistamos dezenove profissionais e realizamos uma observação empírica do cotidiano na redação. Neste artigo, destacamos como os jornalistas do Diário, submetidos à nova função de elaborar registros audiovisuais, viram-se envoltos em uma cultura híbrida, entre a lógica cultural do impresso e a lógica cultural do digital (SANTAELLA, 2007), a ponto de se reconhecerem como jornalistas multimídia e definirem, com base em sua vivência prática, as características que compõem esse novo perfil de profissional.
\end{abstract}

\section{Palavras-chave}

Jornalismo multimídia; jornalismo impresso; lógicas culturais.

\begin{abstract}
This article presents some results from a master's degree research, concluded in 2011. The investigation which embodied the thesis intended to comprehend the construction of the identity from print journalists who work at Diário do Nordeste, a newspaper from Ceará, due the introduction of new mobile technologies in the professional routine. Specifically, we analyzed how the use of a cellphone for recording digital videos, conveyed at the newspaper's website from 2008 to 2010, affected the employees' cognitive skills (GUERRA, 2008), required to the daily exercise of journalism, and their own identities (HALL, 2008; 2006; 2000). So, we interviewed nineteen professionals and did an empiric observation of the everyday in the newsroom. In this article, we detached how the Diário's journalists, submitted to the new function of making audiovisual records, found themselves involved in a hybrid culture, between print cultural logic and digital cultural logic (SANTAELLA, 2007), the point of recognize themselves as multimedia journalists and define, based on their own practical experience, the technical features of this new professional profile.
\end{abstract}


Estudos em Jornalismo e Mídia - Vol. 9 N² 2 - Julho a Dezembro de 2012

ISSNe 1984-6924

\section{Keywords}

Multimedia journalism; print journalism; cultural logic.

Artigo recebido em 05/03/2012

Aprovado em 22/04/2012 
a escala de evolução biológica das espécies, somos todos homo sapiens, caracterizados, principalmente, pela postura ereta, cérebro desenvolvido, capacidade comunicativa e manuseio de objetos, o que nos diferencia sensivelmente de outras espécies animais. Contudo, culturalmente falando, o homo sapiens encontra-se em um processo contínuo de transformação.

Do homem tribal, para quem o sentido do mundo era mediado pela oralidade, passando pelo letrado, cuja alfabetização e escrita fazem-no deixar a tribo e tornar-se civilizado, ao pós-humano, que desenvolve uma relação quase simbiótica com os dispositivos maquínicos. O que se verifica em comum a todos esses momentos de desenvolvimento cultural é a instituição de uma nova relação dos sujeitos com a realidade, impulsionada pelo uso de tecnologias diferentes.

As apropriações que os homens fazem das tecnologias irão incidir também em suas identidades, pois, como observa Martino (2010), a identidade diz respeito aos discursos e narrativas dos sujeitos que dão sentido à realidade e os posicionam nessa mesma realidade. Portanto, quando as tecnologias alteram a relação do homem com os signos ao seu redor, elas consequentemente repercutem na constituição de suas identidades.

À medida que novos aparatos comunicativos surgem, a percepção do mundo pelo homem se altera e, junto com ela, sua capacidade cognitiva e de se relacionar com seus pares.

\begin{abstract}
A civilização se baseia na alfabetização porque esta é um processamento uniforme de uma cultura pelo sentido da visão, projetado no espaço e no tempo pelo alfabeto. Nas culturas tribais, a experiência se organiza segundo o sentido vital auditivo, que reprime os valores visuais. A audição, à diferença do olho frio e neutro, é hiperestética, sutil e todo-inclusiva. As culturas orais agem e reagem ao mesmo tempo. A cultura fonética fornece ao homem os meios de reprimir sentimentos e emoções quando envolvidos na ação. Agir sem reagir e sem se envolver é uma das vantagens peculiares ao homem ocidental letrado (MCLUHAN, 2007, p. 105).
\end{abstract}

Apesar de preocupar-se com as alterações ensejadas pelos meios elétricos, McLuhan (2007) dedicou boa parte de sua obra para explicar a lógica da era de Gutenbergi, marcada pela construção de um modelo cultural que acompanha o homem por mais de cinco séculos e que, na perspectiva do autor, "reprime" certa dinâmica comunicativa ancestral, dominante no modelo de sociedade tribal. Não nos interessa, 
aqui, elaborar juízos de valor sobre vantagens ou desvantagens da lógica cultural oral em relação à lógica cultural escrita (ou vice-versa), mas apenas demarcar que a predominância de uma dada lógica, em um período específico, conduz a formações culturais diferentes.

Certamente, a invenção da imprensa, com a disseminação do livro e de tantas outras descobertas da era moderna, foi determinante de uma revolução do imaginário humano, criando processos de subjetivação que, através dos séculos, se construíram e desconstruíram num jogo de disciplina e descontrole de si, do outro e das condições de sociabilidade (VILLAÇA, 2002, p. 21).

Há aproximadamente três décadas esse estado de coisas instaurado com a modernidade, de que nos fala Villaça (2002), vem sendo repensado nos círculos acadêmicos e alterado na vivência cotidiana com a tradução do mundo em informações compostas a partir de códigos binários, ou seja, a informatização. As transformações são tão profundas que obrigam o repensar de noções clássicas como territorialidade, espaço e tempo únicos, história linear e até mesmo da própria ideia de realidade.

Porém, todas essas transformações não foram suficientes para suplantar o homo typograficus, definido por McLuhan (2007), mas para delinear os contornos de um novo sujeito, que não consome livros, mas aplicativos; que se comunica em tempo real e cuja presença deixa de estar atrelada à materialidade física. A esse novo homem, Luiz Martino (2010, p. 174) chama de homo pixels.

Em uma escala evolutiva darwiniana, o homem tipográfico já deveria ter sido superado pelo homem pixel. No entanto, o que se observa é a convivência entre homens vinculados a modelos culturais diferentes expressos, sobretudo, nas mídias de que se utilizam para comunicar. Assim, grosso modo, quem opta por ler o jornal impresso tende ao modelo cultural tradicional, já aqueles que visualizam as notícias na tela de um tablet demonstram intimidade com a cultura digital ${ }^{\mathrm{ii}}$. No entanto, o que se verifica hoje é a convivência de hábitos associados tanto a mídias e tecnologias tradicionais como o impresso, quanto a novas tecnologias digitais. Esse cenário é descrito por Lúcia Santaella (2007) como de convivência, coexistência de diferentes lógicas culturais.

Em uma esfera micro, num plano mais localizado, especificamente, na redação do Diário do Nordeste, podemos identificar esse jogo de interações entre a cultura do impresso e a cultura do digital. Desde a informatização das redações jornalísticas ainda nos anos de 1980, nos periódicos de circulação nacional como a Folha de São Paulo e, no Ceará, mais especificamente nos anos de 1990 quando o Diário, em uma ação pioneira, adquire microcomputadores para a redação, que o jornalismo adentra nessa 
nova formação cultural. Esta que se complexifica com a adoção das novíssimas tecnologias de informação e comunicação.

Munidos de aparelhos celulares multifuncionais, gravadores digitais, pen drives e contas de e-mail corporativo ${ }^{\text {iii }}$, os repórteres do impresso partilham do uso ou acesso, no plano pessoal e profissional, aos recursos da cultura digital contemporânea. Contudo, o produto do trabalho desses jornalistas está atrelado ainda à cultura do impresso, sua plataforma massiva de veiculação. Mas eles, os sujeitos, transitam pela cultura digital - não vem ao caso demarcar se com ou sem desenvoltura - demonstrando que convivem com essas diferentes lógicas culturais.

Eu tenho celular em que recebo três e-mails, é conectado à internet. Posso dizer que estou conectado 24 horas por dia. Sempre checando Facebook, internet, direto. Realmente, eu sou muito preocupado e antenado com essas coisas (JORNALISTA 1, 2010).

Eu me adapto muito bem às novas tecnologias. Tenho quatro e-mails, Orkut, estou no Facebook, tenho um blog, sigo vários blogs, me comunico com os blogueiros e possuo celular com TV, câmera e leitor de música e rádio (JORNALISTA 3, 2010).

Não tenho blog, mas tenho perfil em redes sociais, no Twitter, Orkut. Não tenho no Facebook ainda. Mas, no trabalho, minha relação com essas ferramentas é de amor e ódio. De amor porque é por meio do Twitter que a gente fica sabendo da maioria das coisas, a morte do Michael Jackson, por exemplo, eu soube pelo Twitter, que, geralmente é a primeira página que eu abro quando ligo o computador, não é mais site de notícia. E, de ódio, porque ele te dispersa. O Twitter aberto a manhã inteira te dispersa, é triste, mas é verdade (JORNALISTA 4, 2010).

Eu sou à moda antiga, porque eu gosto de ler deitada. Para mim, ainda é uma coisa assim como livro, de ler na rede. O prazer é diferente de estar na frente do computador, lendo no computador. Mas lógico, durante o dia eu sempre abro o UOL para ver notícias. Hoje, para mim, a internet está muito mais presente do que a televisão, porque não dá tempo assistir. Eu não sou de ver telejornal na internet, mas, pelo menos, ficar de vez em quando abrindo para atualizar as notícias eu faço, mas principalmente o $U O L$ e os sites do O Povo e do Diário, eu faço, frequentemente durante o dia, mas se for para ler mesmo, é pelo impresso (JORNALISTA 5, 2011).

Eu tinha Orkut, desfiz porque eu acho que não tenho necessidade, é só para as pessoas ficarem sabendo da sua vida, porque para você usar meramente para a comunicação é muito mais fácil você usar o $M S N$. Agora, assim, eu não desconheço a importância que elas têm na comunicação. Mas para mim, para minha vida pessoal, não há necessidade (JORNALISTA 7, 2010). 
O que os depoimentos dos profissionais do Diário do Nordeste nos revelam é que eles "passeiam" pelas lógicas culturais, mas demonstram certa filiação a um modelo específico. O que irá determinar isso é exatamente a negociação estabelecida por meio do uso da tecnologia aos interesses pessoais e profissionais e a própria subjetividade de cada um. Esses sujeitos se posicionam no movimento entre as tradições e as transformações. Conforme Santaella (2007, p. 129), "isso se explica pelo fato de que a cultura humana existe num continuum, ela é cumulativa, não no sentido linear, mas no sentido de interação incessante de tradição e mudança, persistência e transformação".

Toda essa explanação sobre as lógicas culturais com as quais convivemos na atualidade e como os hábitos dos profissionais se enquadram nesse cenário demonstra $o$ quão difícil é para o jornalista se definir na contemporaneidade aos moldes de uma segmentação marcada pela atividade voltada para um meio específico (repórter de impresso, repórter de TV, repórter de rádio ou repórter de web, por exemplo).

Ao mesmo tempo, como observa Bourdieu (1989), a definição de si mesmo desponta como uma necessidade, sobretudo, no âmbito profissional.

\begin{abstract}
A gestão dos nomes é um dos instrumentos de gestão da variedade material e os nomes de grupos - sobretudo de grupos profissionais registram um estado das lutas e das negociações a respeito das designações oficiais e das vantagens materiais e simbólicas que lhes estão associadas (BOURDIEU, 1989, p. 148).
\end{abstract}

A atribuição de um nome para si no campo profissional, como observa o autor, é também uma forma de distinção e de exercício do poder simbólico. Portanto, para os jornalistas do Diário, a atribuição de uma dada alcunha (jornalista de impresso ou jornalista multimídia) repercutirá na posição social que ocupam na redação. É interessante notar ainda que a definição dos profissionais será também influenciada pelos hábitos culturais ou filiação a uma determinada lógica cultural. Dessa forma, quando o jornalista se define como "de impresso", ele se posiciona em uma lógica cultural do impresso, associada ao homem tipográfico de McLuhan (2007). Consequentemente, o jornalista multimídia está mais próximo do homem pixel de que fala Martino (2010).

\title{
Homens pixels
}

A definição de jornalista multimídia ainda não está muito clara, seja no mercado, na própria academia ou no imaginário dos profissionais, afinal, é um perfil profissional 
que está em pleno processo de construção. As explanações abaixo dadas pelos jornalistas do Diário mostram como esse perfil é delineado em um terreno móvel e ora voltado para referências tradicionais do Jornalismo (associadas ao campo do impresso), ora completamente novas, motivadas pela lógica digital ou cibercultural.

Ser repórter multimídia é estar sempre pesquisando novas funções nos equipamentos, fuçando a internet. Vendo o que está sendo produzido aqui no Brasil e lá fora, na internet, nas viagens, trocando ideias. Ser repórter multimídia é ser inquieto. E eu acho que todo repórter deveria ser inquieto. $\mathrm{O}$ repórter tem que ser inquieto. Eu acho que está no cerne. E outra coisa, não é por nós sermos, nos considerarmos repórteres multimídia, que vamos nos esquecer da importância do produto impresso. A gente se esmera para fazer o produto impresso da melhor maneira possível. Afinal, nós somos contratados para isso. $\mathrm{O}$ nosso produto impresso é realmente a cereja do bolo, mas o repórter multimídia está sempre no entorno (JORNALISTA 1, 2010).

$\mathrm{Na}$ fala do jornalista 1, encontramos a referência a uma tradição jornalística universal, quando ele afirma que "todo repórter deve ser inquieto" e a especificidade do repórter multimídia, ao ver dele, está no manuseio da tecnologia ou no que Dominique Wolton (2006) define como performance técnica, e no domínio da internet, espaço de expressão por excelência da lógica cultural digital. Ou seja, o depoimento mostra que a filiação a uma cultura do impresso ainda é muito forte no imaginário profissional desse jornalista.

Por sua vez, o jornalista 2 naturaliza a prevalência de uma lógica cultural digital ao identificar que esta se mostra presente no processo de produção jornalística, independente da plataforma em que o produto será veiculado.

Eu vejo de duas formas. O jornalista que se municia de informações usando ferramentas multimídia e o jornalista que produz para a multimídia, acho que tem essa diferença. Mas, de qualquer forma, eu acho que as ferramentas multimídias são fundamentais para a função de jornalista, sejam elas para servir como fonte de informação para começar a trabalhar o que você vai passar ou para você informar, porque existe um público para isso e é um público que cresce. A tendência é a internet se popularizar cada vez mais e crescer. Então, acho que a gente não pode ser avesso. Não é que eu seja avesso, é que eu me sinto mais à vontade no impresso (JORNALISTA 2, 2010).

O profissional 4, por outro lado, pressupõe que o jornalista é um profissional

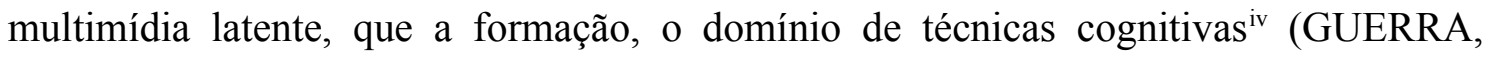
2008), ou seja, o conjunto de saberes que orientarão a prática jornalística devem 
prepará-lo para tal, mas que este só irá passar da multimídia em potência para a multimídia em ato, quando o mercado assim requerer dele.

É ser capaz de, se você ficar amanhã desempregado, e for chamado pra uma rádio, você não precisar fazer um curso de rádio. Você já chegar lá sabendo como é. Ou você ser contratado por um site e só mudar o botãozinho de impresso pra online e já sair uma matéria online. Mas, provavelmente, o que dá isso para qualquer profissional é a vivência e a minha vivência profissional foi assessoria de imprensa e impresso (JORNALISTA 4, 2010).

De forma não tão elaborada, o informante 6 considera a multimidialidade como sinônimo de domínio de diferentes linguagens, processo este que está também associado ao desenvolvimento das técnicas cognitivas dos profissionais. E, ao mencionar a conexão ininterrupta, explicita sua filiação de pensamento à lógica cultural digital, na qual a palavra conexão implica interligação entre sujeitos e máquinas e a própria mediação da conexão dos sujeitos entre si e com o mundo por meio de aparatos digitais. "Dominar essas diferentes linguagens e estar conectado também. O multimídia hoje, pra mim, também tem esse tom de conexão. A pessoa tem que estar ligada." (JORNALISTA 6, 2010).

O depoimento do jornalista 10, por sua vez, pode soar vago, mas apela para o território das referências tradicionais da comunicação jornalística. Sem fazer referência ao impresso ou a ferramentas digitais, ele também apela para a formação cognitiva do profissional que deve capacitá-lo para ser um jornalista global, universal e não segmentado por temas de cobertura ou domínio de linguagens específicas. Já a fala do profissional de número 11 completa o raciocínio do colega agregado às noções cognitivas do jornalista os conhecimentos em torno das especificidades dos meios em que as informações serão veiculadas e da adequação das diferentes linguagens a eles especificamente.

$\mathrm{Eu}$ acho que é englobar todas as possibilidades de comunicação, porque eu, como repórter, sou jornalista, comunicadora, eu estudei comunicação. Então, eu busco todas as ferramentas na comunicação, para ser completa (JORNALISTA 10, 2010).

É ter condições de adaptar a linguagem, de ter essa noção de espaço, de que a leitura é mais rápida, de que você tem que condensar as informações de forma que aquela pessoa não se canse e pensar na imagem no layout que o conteúdo vai ter. Porque só jogar o texto porque ele menor, mais objetivo, também não funciona. Você tem que pensar nisso tudo (JORNALISTA 11, 2010). 
A conexão, a busca de informações e a versatilidade de como construir os conteúdos informativos utilizando-se de diferentes meios marca a resposta do jornalista 12. A exemplo de outros colegas já citados, ele tende a se filiar a uma lógica digital ao se valer do próprio vocabulário dessa formação cultural, afinal, o termo "conectado" nos remete diretamente às novas tecnologias e, sobretudo, à internet, componentes dessa lógica cultural ciber. ou digital.

É um repórter que tem que estar ligado a tudo. Muitas vezes, a gente diz que tal pessoa é multimídia, porque ela faz tudo. Mas, na verdade, o multimídia, pra mim, é estar conectado onde a informação possa chegar, seja de que forma for (JORNALISTA 12, 2010).

Já o depoimento do informante 16 remete à definição de profissional multitarefa elencada por Salaverría \& Negredo (2008). Um “super” jornalista que domina diferentes linguagens e produz conteúdos para diferentes meios ou plataformas integradas. Perfil este, como bem colocam os autores, estimulado pelo mercado, mas que deságua na sobrecarga de trabalho do jornalista e na sua iminente improdutividade, afinal, não consiste em uma prática simples para uso na rotina do hard news por exemplo.

Ao apontar que esse modo de comportamento é uma forma de renovação, o próprio profissional mostra sua "aceitação" ou "conformismo" com o discurso das empresas de comunicação (SALAVERRÍA \& NEGREDO, 2008). A justificativa para o posicionamento desse profissional está no próprio modelo de "jornalismo multimídia" adotado na sua prática, em que o repórter do impresso passa a agregar à sua rotina de trabalho a função de realizar vídeos para serem veiculados no portal do próprio jornal. "Eu acho que, para mim, é aquele que faz além das atribuições, que era fazer só uma, são várias. É essa multiplicação que o repórter tem que entrar. Ir atrás, ir atrás. Sempre se renovando, no caso." (JORNALISTA 16, 2010).

No encerramento das definições do perfil ou atribuições do jornalista multimídia, temos as observações do profissional 17, que se mostram, em virtude das anteriores, a mais completa em relação ao ideal de jornalismo multimídia que colocam os autores Salaverría \& Negredo (2008).

Pensar estrategicamente que/como conteúdo deve ser trabalhado em cada meio, conforme suas características e potencialidades. Exemplo: em pleno confronto entre grevistas e policiais, uma caneta na mão pode retratar a crônica de uma greve, desenvolver perfil de um integrante de cada um dos lados, contextualizar com precisão e hiperlinks a greve, apontar o histórico das últimas paralisações, etc. Uma câmera 
fotográfica na mão pode flagrar bastidores da greve numa perspectiva estética, produzir "narrações fotográficas" (sequência de fotos de um grevista em plena ação com áudio-depoimento acoplado), etc. Uma filmadora na mão pode buscar o "som da greve", documentar em corte seco e cru os principais flagras e movimentações, etc. (JORNALISTA 17, 2011).

Para este informante, o jornalismo multimídia agrega a adequação de diferentes linguagens às especificidades do fato. Sendo assim, conforme essa perspectiva, para ser jornalista multimídia, é preciso ter o domínio técnico de códigos linguísticos, das ferramentas que o meio disponibiliza - no caso citado por ele, a internet, já que menciona o hiperlink - e saber como articular esses recursos às definições de notícias, aos critérios de noticiabilidade (da esfera das técnicas cognitivas), construindo assim uma narrativa jornalística completa. Essa exemplificação dada pelo jornalista 17 denota ainda sua filiação à lógica cultural digital, pois este reconhece a internet como meio potencialmente multimidiático ao enumerar seu ideal de produção multimídia.

\section{Mais que multimídia, jornalistas convergentes}

Em linhas gerais, as definições para jornalista multimídia dadas pelos profissionais do Diário giram em torno das linguagens midiáticas e da conexão, ou seja, de que esse jornalista precisa estar sempre atualizado, qualidade essa que atribuímos ao homem pixel, o sujeito vinculado à cultura digital, sempre conectado, ao mundo e a outros sujeitos, por meio da tecnologia. Nesse sentido, para que o jornalista seja multimídia não é necessário ser multitarefa (SALAVERRÍA \& NEGREDO, 2008), mas sim estar sintonizado com o tempo presente, caracterizado pela presença enfática das mídias e lógica digital em nosso cotidiano.

Contudo, apesar dos dezenove entrevistados terem delineado o perfil do jornalista multimídia ${ }^{\mathrm{v}}$, somente cinco deles se definiriam como tais. E, para tal, valeram-se de algumas das características apresentadas anteriormente, como conexão contínua com a atualidade, manuseio das novas tecnologias digitais e ainda dominação de diferentes linguagens midiáticas.

O jornalista 1, profissional com 15 anos de atuação no Diário, encaixa-se no perfil de multimídia porque, literalmente, produz conteúdos tanto para o impresso, quanto para o online. Além de realizar os vídeos, ele atualiza o blog da editoria para a qual trabalha no DN Online e declara estar sempre conectado à internet por meio de 
dispositivos móveis, fazendo assim com que se posicione no território da cultura digital e, portanto, defina-se como jornalista multimídia.

Eu vi nascer o Portal (Verdes Mares). Eu vi que era só uma pessoa. E profetizaria, não, isso é muita pretensão dizer. Mas porque eu já tinha lido, sabia como ia ter peso no meio de comunicação a questão da internet. Os profissionais estão aí trabalhando direto. É fundamental, volto a dizer, que o repórter não fique só no feijão com arroz. Que ele saiba trabalhar multimídia para que ele consiga novos desafios, ofereça novas coisas. Então, eu também me considero um repórter multimídia (JORNALISTA 1, 2010).

O jornalista 6, apesar de ser um profissional do online e, portanto, lidar com um meio que é multimídia por natureza, ancora sua definição de multimídia na capacidade que o jornalista tem de se adequar ao trabalho para diferentes mídias. O perfil traçado por ele se aproxima do que Salaverría \& Negredo (2008) definem como jornalista multiplataforma, um especialista em um dado assunto, capaz de produzir conteúdos para diferentes mídias ou plataformas.

Multimídia porque eu já trabalhei em vários veículos. A internet tem uma coisa bacana porque ela se aproxima mais da TV e do rádio do que do impresso. Inicialmente falavam que ia acabar com o impresso, mas não. A gente lida muito com vídeo, muito áudio, a interação, etc. Então, o conceito de multimídia está no fato de você saber lidar com várias mídias. Por exemplo, a gente está no momento produzindo webcast. A gente tem um estúdio, aliás um cenário próprio, câmera própria, canopla, materiais de televisão nosso e a gente produz material de vídeo. Então, esse repórter do online, ele tem que estar preparado para fazer uma passagem. Tipo, eu sou de impresso, deixo minha barba crescer, mas no dia que a editora disser: "Você vai ter que fazer uma passagem ao vivo para o streaming do Diário", aí eu vou ter que ir lá tirar minha barba, ir lá no figurino, pegar e fazer. Porque é uma característica multimídia. Eu me sinto habilitado, me sinto capaz de ir na rádio e dizer: "olha, estou aqui ao vivo, direto da Praça do Ferreira", por mais que eu tenha problema de respiração, mas eu vou passar a informação e se tiver de fazer televisão eu vou fazer. É lidar com as várias mídias (JORNALISTA 6, 2010).

O jornalista 16 encontra no domínio de linguagens diferentes a conceituação para o exercício do jornalismo multimídia. Em sua fala, porém, encontramos ainda o tom de "naturalidade", conforme Hall (2003), de que é preciso se adequar aos novos tempos para se manter no mercado.

Eu me considero jornalista multimídia e acho super legal. Acho que a aquisição de novas linguagens é fundamental hoje. Acho que nós vivemos em um período "darwiniano", é uma evolução. Se você não 
evoluir, você está fora do mercado. E o pior é que é (JORNALISTA $16,2010)$.

O profissional 12, por sua vez, recorre ao uso dos recursos multimídia como ferramentas de trabalho para se identificar com esse novo perfil. É interessante ressaltar que a multimídia a que o informante se refere é a própria internet. Nesse sentido, o novo profissional seria um homem conectado com seu tempo, um homem pixel, que se integra à cultura digital. "Eu sou uma repórter multimídia. Porque eu utilizo os recursos multimídia pro meu trabalho. Não necessariamente que o produto do meu trabalho seja multimídia." (JORNALISTA 12, 2010).

E, por fim, o jornalista 17 embasa seu posicionamento no domínio de diferentes linguagens, como a audiovisual e fotográfica e, principalmente, na capacidade de articular esses códigos, o que Salaverría \& Negredo (2008) consideram como o diferencial dos profissionais no universo da convergência jornalística. Mais do que multimídia, a definição do profissional 17 aproxima-se do perfil de jornalista convergente, que não necessariamente precisa ser multitarefa, mas ter competência cognitiva relativa ao impresso, ao online e ao audiovisual e saber articulá-las.

Produzo vídeos e áudios. Executo elementos básicos em fotos. E o que, a meu ver é tão relevante quanto, penso de forma multimídia, inclusive em elementos que não domino (infografia, animações, realidade aumentada, fotos $360^{\circ}$, games, etc.) (JORNALISTA 17 , 2011).

Nossos entrevistados que se definem como profissionais multimídia apresentam, assim, competências cognitivas relativas ao manuseio de dispositivos tecnológicos, ao domínio da linguagem impressa, audiovisual e, sobretudo, partilham da lógica cultural digital. Essa definição marca um posicionamento que irá culminar na construção da identidade de cada um desses jornalistas no campo profissional. A posição de jornalista multimídia abarca assim outras posições identitárias tradicionais no campo jornalístico, como a do impresso e a do audiovisual (a fotográfica também, citada por dois entrevistados) e as coloca em articulação com a cultura digital.

Ou seja, a posição identitária multimídia definida pelos profissionais é móvel, fluida, enquadrando-se no perfil que optamos por identificar como de jornalista convergente. A escolha pelo termo convergente em vez de multimídia é uma maneira de evitar o aspecto negativo que esse adjetivo recebe por conta de sua indefinição e dos modelos deficientes e precários de jornalismo multimídia que são, 
muitas vezes, postos em prática no mercado. O termo convergente, por sua vez, remete às discussões em torno da convergência jornalística (SALAVERRÍA \& NEGREDO, 2008; FRAGOSO, 2006; APPLEGREN, 2005), mais abrangentes e que tomam a multimidialidade como uma característica desse processo mais amplo.

Os depoimentos aqui transcritos nos mostram a negociação entre diferentes lógicas culturais vivenciadas pelos jornalistas do Diário do Nordeste. Apesar de muitos dos nossos entrevistados definirem-se como "de impresso" e justificarem essa escolha pela ancoragem em uma lógica cultural do impresso, é preciso reconhecer que eles não são mais homens tipográficos puros. Quando cinco profissionais se afirmam como jornalistas multimídia, está claro que eles reconhecem a presença da lógica cultural digital no cotidiano de trabalho.

Com isso, abrem um caminho para a consolidação do perfil de jornalista convergente, que não precisa se filiar a uma formação cultural específica, mas reconhecer a convivência com diferentes lógicas que vão da oralidade ao digital, e saber adequá-las às necessidades profissionais, ou seja, à construção de discursos que fazem a mediação da realidade.

\section{Referências Bibliográficas}

APPELGREN, Esther. The influence of media convergence on strategies in newspaper production. Tese de doutorado defendida na KTH, em Estocolmo, Suécia, 2005, p. 41-51.

BOURDIEU, Pierre. O poder simbólico. Lisboa: Difel, 1989.

FRAGOSO, Suely. Reflexões sobre a convergência midiática. In Líbero, São Paulo, v. viii, n. 15-16, p. 17-21, 2006.

GUERRA, Josenildo Luiz. O percurso interpretativo na produção da notícia - verdade e relevância como parâmetros de qualidade jornalística. São Cristóvão: Editora UFS; Aracaju: Fundação Oviêdo Teixeira, 2008.

HALL, Stuart. Da Diáspora - identidades e mediações culturais. Belo Horizonte: Editora UFMF, 2 reimpressão, 2008.

A identidade cultural na pós-modernidade. Trad. Tomaz Tadeu da Silva, Guaraciara Lopes Louro. 11. ed. Rio de Janeiro: DP\&A, 2006.

. Quem precisa de identidade? In SILVA, Tomaz Tadeu da (org). Identidade e diferença - a perspectiva dos estudos culturais. Petrópolis: Vozes, 2000.

MCLUHAN, Marshall. Os meios de comunicação como extensões do homem. São Paulo: Cultrix, 2007. 15 reimpressão.

MARTINO, Luiz Mauro Sá. Comunicação e identidade. Quem você pensa que é? São Paulo: Paulus, 2010.

SALAVERRÍA, Ramón; NEGREDO, Samuel. Periodismo integrado - convergencia de medios y reorganización de redacciones. Universidade de Navarra, Espanha, 2008.

SANTAELLA, Lúcia. Linguagens líquidas na era da mobilidade. São Paulo: Paulus, 2007.

Da cultura das mídias à cibercultura: o advento do pós-humano. In Revista FAMECOS, Porto Alegre, n. 22, dezembro de 2003.

VILLAÇA, Nízia. Impresso ou eletrônico? Um trajeto de leitura. Rio de Janeiro: Mauad, 2002.

WOLTON, Dominique. É preciso salvar a comunicação. São Paulo: Paulus, 2006. 
${ }^{\text {i } E m ~ 1455, ~ o ~ a l e m a ̃ o ~ J o h a n n e s ~ G u t e n b e r g ~ c r i o u ~ a ~ p r e n s a ~ d e ~ t i p o s ~ m o ́ v e i s ~ e ~ c o m ~ e l a ~ r e v o l u c i o n o u ~ a ~ h i s t o ́ r i a ~ d a ~ h u m a n i d a d e . ~}$

ii Claro que precisaríamos investigar outros hábitos culturais desses sujeitos para afirmar com convicção sua filiação a uma lógica cultural específica.

iii É importante ressaltar que quase todos os jornalistas em atividade na redação dispõem de um e-mail corporativo pessoal. Contudo, nos idos de 2007, ainda havia uma parcela significativa de jornalistas que não tinham acesso a essa ferramenta (e não por falta de interesse da parte do jornalista) o que caracterizava, inclusive, uma relação de diferenciação, já que os repórteres com e-mail eram vistos como privilegiados, profissionais mais importantes pelos demais. Na atualidade, somente os prestadores de serviço não possuem uma conta de e-mail própria. Nesse caso, para trocar correspondências eletrônicas, precisam ter acesso ao e-mail da editoria para a qual trabalham, caso o editor permita, pois o acesso a contas de e-mail pessoal é proibido para todos.

${ }^{i v}$ Conforme Guerra (2008), o trabalho jornalístico requer o domínio de três técnicas - cognitiva, de conduta e de produção - que irão nortear o comportamento, a elaboração dos conteúdos e a responsabilidade social desses profissionais. "Essas técnicas têm um componente normativo e conceitual (as técnicas cognitivas), que definem como deve ser realizado o trabalho, e um componente prático (as técnicas de conduta e de produção), que visam efetivar a orientação normativa e conceitual no processo de produção jornalística. Em função disso, podemos dizer que as técnicas de conduta e de produção representam a ação metodologicamente orientada pelas técnicas cognitivas. Quanto mais eficaz e eficientemente os profissionais manejarem essas técnicas, maior a chance de obterem um desempenho satisfatório." (2008, p. 173).

${ }^{\vee}$ Para esse artigo, selecionamos apenas os depoimentos que consideramos mais relevantes, pois muitos deles soavam até repetitivos.

Este artigo e todo o conteúdo da Estudos em Jornalismo e Mídia estão disponíveis em http://www.periodicos.ufsc.br/index.php/jornalismo/index

Estudos em Jornalismo e Mídia está sob a Licença Creative Commons. 